\title{
Polymerase Chain Reaction Multiplication for the Detection of Bacterial Isolates Causing Neonatal Sepsis
}

\author{
Utari Hartati Suryani ${ }^{1,2}$, Andri Rezano ${ }^{1}$, Yunia Sribudiani ${ }^{1 *}$ \\ ${ }^{1}$ Department of Microbiology, Faculty of Medicine, Universitas Padjajaran, Indonesia; ${ }^{2}$ Department of Microbiology, Faculty of \\ Medicine and Health Sciences, Universitas Bengkulu, Indonesia
}

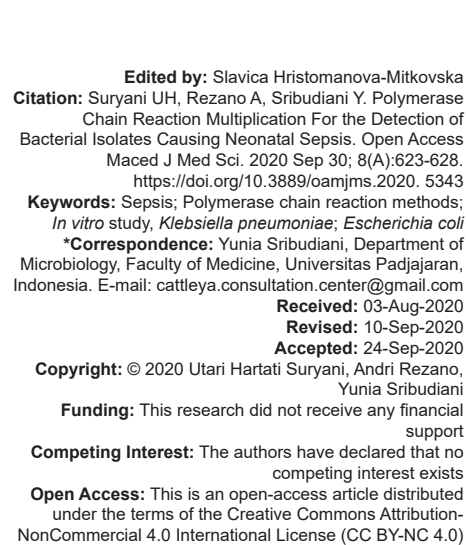

Introduction

Sepsis is a problem that has been one of the leading causes of death in neonates to date [1]. Based on the WHO report in 2015, neonatal sepsis is one of the leading causes of death in children under-5 years in addition to other causes such as pneumonia, diarrhea, and malaria [2]. Indonesia's health profile in 2015 states that neonatal sepsis is the leading cause of death which causes neonatal mortality rate (NMR) to be 19 deaths per 1000 live births, thus contributing to $59 \%$ of infant mortality [3]. Neonatal sepsis is a clinical syndrome caused by the presence of bacteria in the blood accompanied by symptoms and systemic signs of infection that occurs in the first 4 weeks of life after birth [4]. The process of identifying pathogenic microorganisms is essential in determining the clinical condition in neonatal sepsis.

During this time, the detection of microorganisms carried out still uses the gold standard in the form of microorganism culture [1]. This method provides accurate results in the identification of bacteria. Although this method is the gold standard, there are still many shortcomings, including the need for a long time in the process of about 48-72 $\mathrm{h}$, and the number of blood specimens is quite significant to reach $20 \mathrm{~mL}$ [1], [5], [6], [7], [8]. Furthermore, the specimen collection method is inaccurate, and the number of inappropriate specimens can affect the accuracy of the results [7]. This condition results in a longer time needed for bacterial identification. Because of the various problems above, a new detection method as an alternative needs to be developed.

Along with the development of molecular biology in the past few decades, various alternative methods of the detection of molecular-based bacteria have also been developed [7], [8]. Development of various diagnostic products also creates new problems, including the costs required to be able to provide equipment and carry out these examinations, is relatively expensive so that it is still difficult to reach by various health facilities. Alternative methods to detect molecular-based microorganisms with simple devices need to be developed to be able to meet the desired diagnostic needs at affordable prices.

The main bacteria causing neonatal sepsis at Hasan Sadikin Hospital in Bandung are known to be Gram-negative enteric bacteria such as Klebsiella pneumoniae, Escherichia coli, Enterobacter cloacae, 
and $P$ seudomonas aeruginosa [9], [10], [11]. The various profiles pose a challenge that the diagnostic method to be developed must be able to meet the diagnostic needs where the bacteria that need to be identified do not only originate from one species of bacteria but consist of several species. Based on these considerations, the molecular method that is considered to be an option is polymerase chain reaction (PCR) multiplex, because this method can detect several different target DNAs at the same time [10], [11], [12], [13].

The PCR multiplex method provides an alternative in the world of diagnostic microbiology. The ability of this method can be used to reduce the number of reactions needed to test samples with different targets to save the time and cost required [14], [15]. Through the multiplex PCR method as a more sensitive technology for analyzing patient samples, the problem will be resolved [16]. The important thing when developing a molecular-based diagnostic method such as multiplex PCR is to conduct an original design and PCR optimization process. The study was aimed to develop a multiplex PCR method and to identify bacterial isolates that cause neonatal sepsis in Indonesia with the main target of optimization of an initial design and PCR optimization.

\section{Methods}

This research is an explorative, descriptive study in vitro for the optimization of an initial design and PCR methods for the detection of the main bacteria that cause sepsis neonatorum in Indonesia, namely, bacteria K. pneumoniae, E. coli, E. cloacae, and $P$. aeruginosa. The study was conducted at the Biomolecular Laboratory of the Faculty of Medicine, Universitas Padjadjaran, Bandung, Indonesia. The ethics committee approved this study 1011/UN6.C.10/ PN/2017, October 24, 2017, and adjusted according to the ethics amendment No.07/ UN6.C.10/PN/2017, January 22, 2018.

The initial stage of the research was to do a subculture and manufacture of bacterial isolate stocks. Isolate bacterial ATCC K. pneumoniae ATCC 700603, E. coli ATCC 25922, E. cloacae ATCC 13047, and $P$. aeruginosa ATCC 27853 stored at $-20^{\circ} \mathrm{C}$ were first removed and placed in a safety cabinet. Then allowed to stand for some time, until the isolate was at the ATCC 27853 stored at $-20^{\circ} \mathrm{C}$ first removed and placed in a safety cabinet, then allowed to stand for some time, until the isolate was at the ATCC 27853 stored at a temperature of $-20^{\circ} \mathrm{C}$ room temperature. Subcultures were then performed on Petri dishes which contained nutrient agar medium and were incubated for 16-24 $\mathrm{h}$ at $37^{\circ} \mathrm{C}$. After the incubation period, one bacterial colony was taken and then suspended in a Tryptic Soy Broth
(TSB) $-20 \%$ glycerol medium as much as $1 \mathrm{~mL}$. This suspension is a bacterial isolate stock suspension that will be reused for the isolate subculture process that will be used in the extraction process. For the extraction process, the bacterial stock suspension will be taken slightly in freezing conditions and subcultured on TSB medium as much as $5 \mathrm{~mL}$ and then incubated for 16-24 $\mathrm{h}$ at $37^{\circ} \mathrm{C}$, then followed by isolation of bacterial genomic DNA. Isolation of bacterial DNA from isolates and blood samples was carried out using the Wizard $®$ Genomic DNA Purification Kit (Promega, USA) following the protocol of the manufacturer. The purity of bacterial genomic DNA was measured using NanoDrop TM ND-2000 (Thermo Fisher Scientific, USA), to quantify the extracted DNA

The primer design stages are carried out in silico. The initial step of designing a primer for PCR is to determine the target DNA region/fragment to be amplified for each bacterium to be tested. The primer design is done using the Primer3Plus online software (https://primer3plus.com/cgi-bin/dev/primer3plus.cgi). The target DNA size to be amplified (amplicon) ranges from 300 to 600 base pairs (bp), the lowest melting temperature $(\mathrm{MT})$ of $50^{\circ} \mathrm{C}$ and the highest $60^{\circ} \mathrm{C}$, the length of the primary oligo is between 18 and $25 \mathrm{bp}$ and the GC clamp is $2 \mathrm{bp}$. The primers produced for each target region tested for specificity/accuracy amplify the target region in specific bacteria using the Basic Local Alignment Search Tool (BLAST) PRIMER (https://www. ncbi.nlm.nih.gov/tools/primer-blast/).

In the final stage, an examination is carried out on the primer or target, including the number and position of the corresponding nucleotide bases, the orientation of primer, and distance between the forward and reverse primers. Primer specificity test is done by conducting PCR on the working solution of each primer design using DNA isolation from nine different microorganisms that represent three groups of microorganisms, namely, Gram bacteria (+): Enterococcus faecalis and Staphylococcus aureus, Gram bacteria (-): Stenotrophomonas maltophilia, Acinetobacter baumannii, Salmonella paratyphi A, and Salmonella spp., and several Candida species: Candida albicans, Candida parapsilosis, and Candida glabrata.

PCR optimization using design primers was carried out uniquely using genomic DNA of bacteria that had adequate quality in terms of concentration, namely, at least $\sim 50 \mathrm{ng} / \mu \mathrm{l}$ and excellent purity in terms of OD ratio $260 / 230$ and $260 / 280(\geq 2.0)$. When the PCR uniplex successfully produces a specific amplicon (PCR product) on one size, the analysis of $P C R$ results will be followed by Sanger sequencing and sequencing results analysis using BLAST Nucleotide software (https://blast.ncbi.nlm.nih.gov/Blast .cgi). The next step is to optimize the multiplex PCR gradually (duplex and triplex) using a primer mixture for the specific region of each target bacterium. In each stage of optimization, positive and negative controls will always be used as a form of PCR quality control. 
The next stage is the serial dilution formulation. ATCC bacterial isolates $K$. pneumoniae, $E$. coli, $E$. cloacae, and $P$. aeruginosa were inoculated to the liquid TSB medium for proliferation until they reached the log phase. Take $1 \mathrm{~mL}$ of isolate then do serial dilution using liquid TSB medium, starting from $10^{8}$ to $10^{10}$ cells $/ \mathrm{mL}$. Then, perform the genomic DNA extraction procedure using the Wizard ${ }^{\circledR}$ Genomic DNA Purification (Promega, USA) kit. Detection of bacterial genomic DNA from serial dilution results was performed using a multiplex PCR formulation that was optimized in step 1, and the minimum detection limit obtained would be used as a benchmark for the dilution serial limit to be used in the next step. ATCC bacterial isolates $K$. pneumoniae, $E$. coli, E. cloacae, and $P$. aeruginosa were inoculated to the liquid TSB medium for proliferation until they reached the log phase. Take $1 \mathrm{~mL}$ of isolates and do serial dilution using liquid TSB medium, starting from $10^{8}$ to $10^{10}$ cells $/ \mathrm{mL}$. Bacterial isolates are then centrifuged at 11,000 rpm and then bacterial cell pellets spike in $300 \mathrm{~mL}$ of human blood taken from healthy donors. The results of the spike are then used for human DNA depletion procedures using the Wizard® Genomic DNA Purification (Promega, USA) kit. PCR products were identified by electrophoresis using $2 \%$ agarose gel, 100 volts for $30-60 \mathrm{~min}$. After the electrophoresis process, the agarose gel plates are read in an ultraviolet (UV) cabinet. PCR product sequencing is only carried out for validation that the resulting amplicon is the target region for each bacterium to be tested. This stage is only done once when a specific band ( 1 band) is successfully amplified for each target region. A total of $30 \mu \mathrm{L}$ PCR products on the genes encoded by each bacterial species were prepared, then electrophoresis to see the size of the gene bands encoded on each bacterial species. After that, DNA purification of the PCR product will be sequenced using Sanger sequencer (Thermo Fisher Scientific, USA).

\section{Results}

In this study, primers are designed using 3Plus primers (https://primer3plus.com/), where each primer is designed with the following conditions, such as the primer size ranges from 18 to $25 \mathrm{bp}$; the size of an amplicon 300-600 bp; primer MT 55-60 $\mathrm{C}$, with a temperature difference between forward and reverse of $1-2^{\circ} \mathrm{C}$; the number of $\mathrm{GC}$ components in primary is 40-60\%; the last two sequences at the 3'UTR end are $\mathrm{C}$ or $\mathrm{G}$ or a combination of the two bases (GC clamp).

In this study, the optimization process of the multiplex method was carried out with a composition of a PCR mixed solution: $4 \mu$ INA template (with each species taking $1 \mu$ l DNA template), $25 \mu \mathrm{l}$ MyTaqTM Red Mix (Bioline, Singapore), and $8 \mu$ l primary mixtures for all four species bacteria (consisting of
$10 \mathrm{pmol} / \mathrm{\mu l}$ primers from each forward and reverse of each species), then mixed with sterile aqua distillates until they reach a total volume of $50 \mu \mathrm{l}$. A mixture of solutions for the $\mathrm{PCR}$ reaction on the positive control (from the multiplex optimization process) made with a DNA template composition $(1 \mu \mathrm{l}), 25 \mu \mathrm{l}$ MyTaqTM Red Mix (Bioline, Singapore), and $2 \mu$ primer mixes (consisting of $10 \mathrm{pmol} / \mu \mathrm{l}$ primers from each respectively forward and reverse), then mixed with sterile aqua distillate until it reaches a total volume of $50 \mu \mathrm{l}$. At the same time, for the negative control, it is reacted by adding the four pairs of primers without the addition of a bacterial DNA template. The PCR-TD amplification protocol for the multiplex optimization stage is the same as the duplex optimization stage which is $5 \mathrm{~min}$ at $95^{\circ} \mathrm{C}$ for pre-denaturation, 10 denaturation cycles at $95^{\circ} \mathrm{C}$ for $1 \mathrm{~min}$, annealing at $65^{\circ} \mathrm{C}$ (with a temperature drop of $1^{\circ} \mathrm{C}$ in each cycle, until the temperature becomes $55^{\circ} \mathrm{C}$ ) for $1.5 \mathrm{~min}$, and extension at $72^{\circ} \mathrm{C}$ for 1 minute. This is followed by 25 cycles with denaturation at $95^{\circ} \mathrm{C}$ for $1 \mathrm{~min}$, annealing at $55^{\circ} \mathrm{C}$ for $1.5 \mathrm{~min}$, and extension at $72^{\circ} \mathrm{C}$ for $1 \mathrm{~min}$. The reaction was completed with a final extension for $5 \mathrm{~min}$ at $72^{\circ} \mathrm{C}$. The PCR product at the end of the reaction was confirmed using $2 \%$ agarose gel and photographed with UV transillumination using a gel documentation system. The results of multiplex optimization of PCR of the four species of bacteria that cause neonatal sepsis are shown in Figure 1.

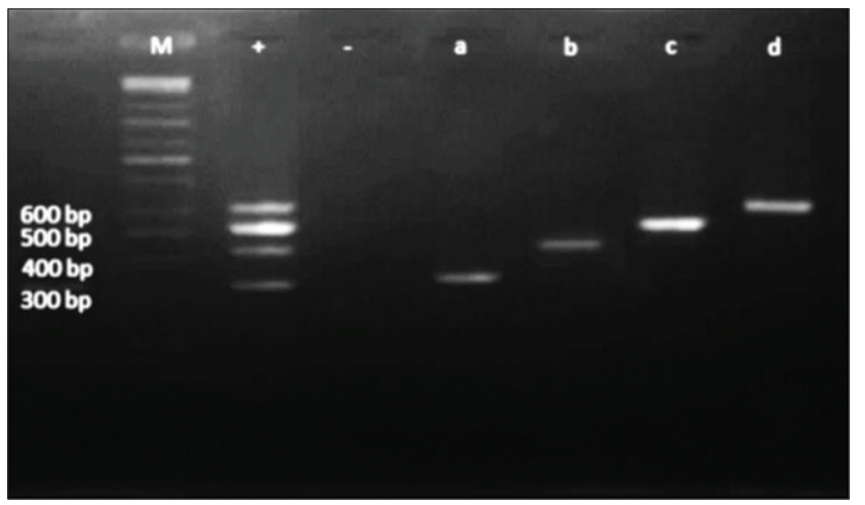

Figure 1: Polymerase chain reaction multiplex optimization results using the touchdown method. Optimization results can be seen in the columns marked with (+), negative controls are shown in columns marked with (-), and for positive control sequentially indicated by the number (a) Klebsiella pneumoniae, (b) Pseudomonas aeruginosa, (c) Enterobacter cloacae, (d) Escherichia coli

Based on the results of sequencing carried out and continued with BLAST sequencing results, it appears that the PCR product that has been produced conforms with the optimization targets that were previously set when doing the primer design. This degree of conformity can be used as proof that the PCR product that has been produced is specific not only visible from the similarity in size to what has been designed but also has the same sequence of nucleotide bases. The level of homology found in all four species based on the results of BLAST in a sequence is as follows: K. pneumoniae 94\%, P. aeruginosa 99\%, E. cloacae $100 \%$, and E. coli $100 \%$ (Figure 2). 


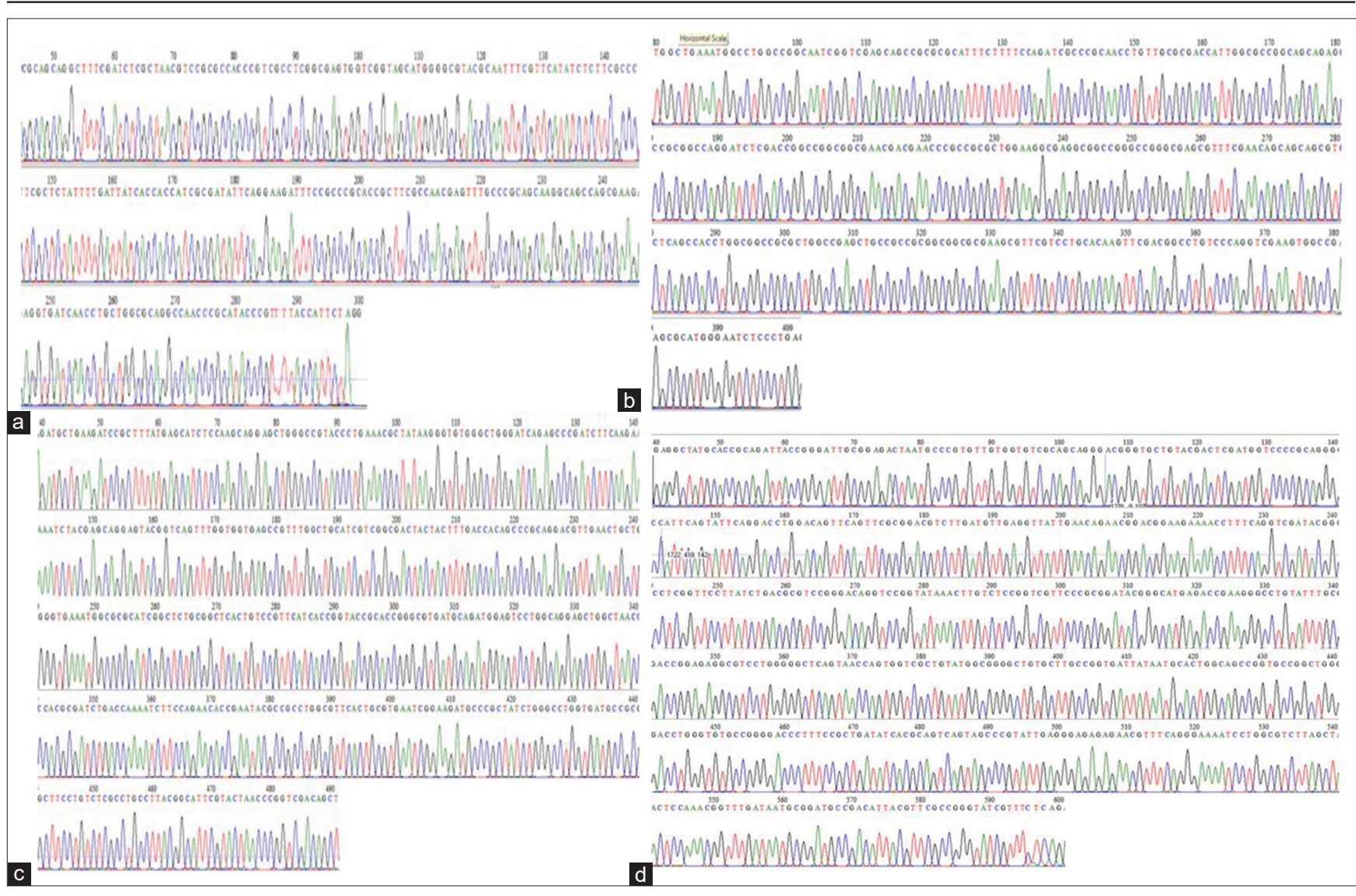

Figure 2: Polymerase chain reaction product sequencing results; (a) wagC gene from Klebsiella pneumoniae, (b) gen ecf from Pseudomonas aeruginosa, (c) impC gene from Enterobacter cloacae, (d) papC gene from Escherichia coli

One other important step that must also be taken when testing a method that will be developed into a new test tool is to test the specificity, efficiency, and sensitivity of the method. For testing the sensitivity level, various methods can be done, one of which is the minimum detection limit test. The amplification protocol was carried out the same as that which had been carried out in the multiplex optimization stage of the previous PCR, namely, using the PCR-TD method, annealing time 1 , annealing temperature $65-55^{\circ} \mathrm{C}$, and 35 cycles. From this process, the result of the minimum detection limit of each species in the sequence was $K$. pneumoniae at $10^{6}$ cells $/ \mathrm{mL}, P$. aeruginosa at $10^{4}$ cells $/ \mathrm{mL}$, E. cloacae $<10^{\circ}$ cells $/ \mathrm{mL}$, and E. coli at $10^{4}$ cells $/ \mathrm{mL}$ (Figure 3).

\section{Discussion}

Primer design is one of the essential components in the process of optimizing the PCR multiplex method. Various problems can be encountered due to errors at this stage, including nonspecific attachment to the DNA template that is not the target, the presence of a dimer primer and allowing the inability to separate and purify DNA amplicons with
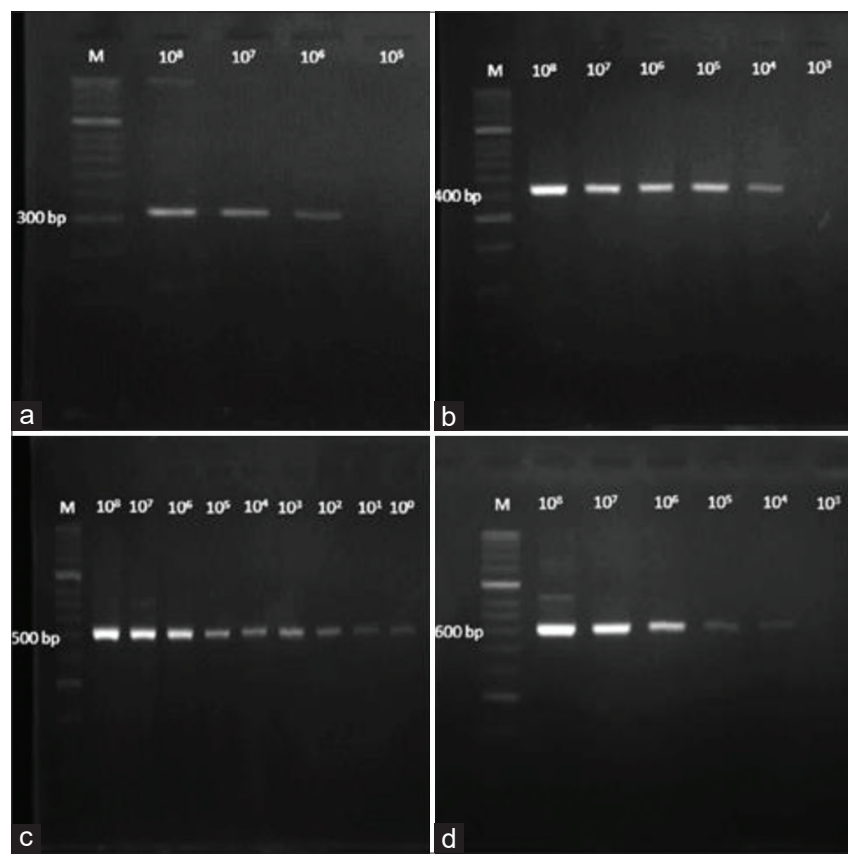

Figure 3: The minimum detection limit of the serial dilution process of each bacterial species, respectively, (a) Klebsiella pneumoniae $=10^{6} \mathrm{cells} / \mathrm{mL}$, (b) Pseudomonas aeruginosa $=10^{4}$ cells $/ \mathrm{mL}$, (c) Enterobacter cloacae $<10^{\circ} \mathrm{cell} / \mathrm{s} / \mathrm{mL}$, and (d) Escherichia coli at $10^{4} \mathrm{cell} / \mathrm{s} / \mathrm{mL}$

the same electrophoretic mobility [17]. Based on these various reasons, the determination specific gene areas 
and specific amplicon sizes will significantly affect the success of optimization (Table 1).

In prokaryotes, genes in the 16s rRNA (rDNA) area have essential functions; this area also has a high universality so that they are often used as targets for phylogenetic research and taxonomic classification. Genes in this area have trunk and knot areas. Although the evolution process has caused the bacterial genomics to tend to change and lose genetic material inherited from previous generations, this area is still relatively similar to previous generations, especially at the node [18]. However, in this study, the area used for the primary design of the four species of bacteria that cause neonatal sepsis is not taken from the 16s rRNA area. This is because references from journals that can be used relating to genes in the $16 \mathrm{~s}$ rRNA area of the four species are still minimal and gene references in that area also have low specificity. In a study conducted by Kaitsu Rantakokko-Jalava relating to the detection of the bacterium Legionella spp., they also had difficulty designing primers from the 16S rRNA and $5 \mathrm{~S}$ rRNA areas because the resulting PCR products could not accurately identify to species level, but only down to species level of the genus [19].

Primer specificity is a crucial component in this study because this method was developed to detect bacteria from four different species and three of the four species are from the same family, namely, Enterobacteriaceae so that the genomes of these three bacteria have relatively high similarity. This background results in specificity testing need to be done to ensure that the desired product will be formed later. In the initial stages, conformity testing can be done in silico using the BLAST. This program is a tool that can be used to detect similarity in the sequence of nucleotide-forming genes or the sequences that exist in proteins. The National Center for Biotechnology Information (NCBI) provides access to the program through the website https://www.ncbi.nlm.nih.gov/tools/primer-blast/.

The related information obtained will allow access to data related to the similarity of nucleotide base sequence identity in a gene so that the similarity of the nucleotide base sequence in other genes can be detected either from the same species or from other species [16]. When testing gene compatibility from $16 \mathrm{~s}$ rRNA areas using BLAST, it is often found that gene references taken from published data not only have similarities with one specific bacterial species but also have nucleotide base sequence sequences up to $>90 \%$ with other bacterial species mainly from the same family. Furthermore, data related to bacterial genes contained by NCBI (https://www.ncbi.nlm.nih.gov/gene) are still quite limited, which include gene-related data in the 16s rRNA area. Frequent changes in data, when compared with data, have been previously published so that in this study, the primary design carried out was more about gene data on the bacterial chromosome and proved to be specific in silico even though it did not originate in the 16s rRNA area. In designing a
Table 1: Primer design

\begin{tabular}{|c|c|c|c|c|}
\hline Bacteria & Gene & Primer (5'-3') & Product size & MT \\
\hline \multirow[t]{2}{*}{ K. pneumoniae } & wacG & CGCAGGCTAAAGTGATGC & 325 & $55-65^{\circ} \mathrm{C}$ \\
\hline & & AGAATGGTAAAACGGGTATGC & & \\
\hline \multirow[t]{2}{*}{$P$. aeruginosa } & ecf & ATGCCTATCAGGCGTTCC & 436 & $55-65^{\circ} \mathrm{C}$ \\
\hline & & TTTTCCACCATGCTCAGG & & \\
\hline \multirow[t]{2}{*}{ E. cloacae } & $i m p C$ & GAGTTTCAGAAGCTGGAGAGC & 533 & $55-65^{\circ} \mathrm{C}$ \\
\hline & рарС & $\begin{array}{l}\text { TCTTCAAAGTCAAAGCTGTCG } \\
\text { TCCGGTCATGGAGTTATACG }\end{array}$ & 623 & $55-65^{\circ} \mathrm{C}$ \\
\hline E. coli & & TCGCTCTGAGAAACGATACC & & \\
\hline
\end{tabular}

aeruginosa: Pseudomonas aeruginosa

primer, various components must also be considered, such as the original size ranges from 18 to $30 \mathrm{bp}$; the size of the amplicon; primary MT with a temperature difference of not more than $3^{\circ} \mathrm{C}$ between forwarding and reverse, and the number of GC components in the primary is $40-60 \%$. These various components must be considered considering the multiplex PCR is a method that mixes several pairs of primers in one reaction so that the compatibility between primers used in the optimization process will determine its success [17].

In this study, primers are designed using 3Plus primers (https: //primer3plus.com/), where each primer is designed with the following conditions, such as the primer size ranges from 18 to $25 \mathrm{bp}$; the size of an amplicon 300-600 bp; primer MT 55-60 $\mathrm{C}$, with a temperature difference between forward and reverse of $1-2^{\circ} \mathrm{C}$; the number of GC components in primary is $40-60 \%$, and the last two sequences at the 3'UTR end are C or G or a combination of the two bases (GC clamp).

The PCR multiplex optimization process itself has various difficulties, including reduced product specificity due to the amplification process for less specific targets. This is more due to the presence of more than 1 pair of primers in a PCR mixed solution [18]. In the process of multiplex optimization of PCR, various components must be considered to form the desired product. In some previous studies, there is the term "trial and error" in the optimization process. The term is used to describe the importance of compatibility between PCR components to be able to produce an appropriate optimization process. One component that plays a key role in this optimization process is primers, where homology, G-C content, and primary concentration will influence the desired product. Ideally, all primer pairs in a multiplex PCR should have similar efficiencies for each target amplification. This condition can be obtained through the use of primers with almost identical annealing temperatures, to obtain these conditions, the primer should be designed with a length of 18-30 bp and containing a G-C base of 35-60\% [18], [19].

\section{Conclusion}

PCR multiplex method using design primers and conventional PCR analysis methods (using agarose 
gel) can be used to detect four species of bacteria that cause neonatal sepsis, namely, K. pneumoniae, $P$. aeruginosa, E. cloacae, and E. coli.

\section{Acknowledgment}

The author would express their gratitude to Medical Research Unit of Faculty of Medicine, Universitas Padjadjaran, Bandung, Indonesia.

\section{References}

1. Pammi M, Flores A, Leeflang M, Versalovic J. Molecular assays in the diagnosis of neonatal sepsis: A systematic review and meta-analysis. Pediatrics. 2011;128(4):973-85. https://doi. org/10.1542/peds.2011-1208

PMid:21949139

2. Paolucci M, Landini MP, Sambri V. How can the microbiologisthelp in diagnosing neonatal sepsis. Int J Pediatr. 2012;2012:120139. https://doi.org/10.1155/2012/120139

PMid:22319539

3. Chan JC, Lee AC, Baqui AH, Tan J, Black RE. Prevalence of early-onset neonatal infection among newborns of mothers with bacterial infection or colonization: A systematic review and meta-analysis. BioMed Central Infect Dis. 2015;15(1):1-16. https://doi.org/10.1186/s12879-015-0813-3

4. Tille PM. Bailey and Scott's Diagnostic Microbiology. St.Loius, Missouri: Elsevier Inc., Mosby Inc.; 2014.

5. Mahon CR, Lehman DC, Manuselis G. Textbook of Diagnostic Microbiology. Maryland Heights: Elsevier Inc.; 2015.

6. Brooks GF, Carroll KC, Morse SA, Mietzner TA. Jawetz, Melnick, Adelberg Medical Microbiology. New York: McGraw-Hill Education, Inc.; 2013.

7. Garibyan L, Avashia N. Research techniques made simple: Polymerase chain reaction (PCR). J Invest Dermatol. 2014;133(3):1-8. PMid:23399825

8. Auckenthaler R, Risch M. Do multiplex PCR techniques displace classical cultures in microbiology? Ther Umsch. 2015;72(2):7785. https://doi.org/10.1024/0040-5930/a000647

PMid:25630288
9. Sint DL, Traugott M. Advances in multiplex PCR: Balancing primer efficiencies and improving detection success. Methods Ecol Evol. 2012;3(5):898-905. https://doi. org/10.1111/j.2041-210x.2012.00215.x PMid:23549328

10. Lebovitz EE, Burbelo PD. Commercial multiplex technologies for the microbiological diagnosis of sepsis. Mol Diagnosis Ther 2013;17(4):221-31. https://doi.org/10.1007/s40291-013-0037-4 PMid:23636778

11. Ahmad N, Drew WL, Lagunoff $M$, Pottinger $P$, Reller $B L$, Sterling CR. Sherris Medical Microbiology. New York: McGrawHill Education; 2014.

12. Murray PR. Rosenthal KS, Pfaller MA. Medical Microbiology. Philadelphia, PA: Elsevier, Saunders; 2013.

13. Ragheb SM, Yassin AS, Amin MA. The application of uniplex duplex, and multiplex PCR for the absence of specified microorganism testing of pharmaceutical excipients and drug products. PDA J Pharm Sci Technol. 2012;66(4):207-317. https://doi.org/10.5731/pdajpst.2012.00871 PMid:22767880

14. Ito R, Shindo $Y$, Kobayashi D, Ando M, Jin W, Wachino J, et al. Molecular epidemiological characteristics of Klebsiella pneumoniae associated with bacteremia among patients with pneumonia. J Clin Microbiol. 2015;53(3):879-86. https://doi. org/10.1128/jcm.03067-14 PMid:25568434

15. Al-Jailawi MH, Zedan TH, Jassin KA. Multiplex-PCR assay for identification of Klebsiella pneumoniae. Int J Pharm Sci Rev Res. 2014;26(1):112-7.

16. Turton JF, Perry C, Elgohari S, Hampton CV. PCR characterization and typing of Klebsiella pneumoniae using capsular type-specific, variable number tandem repeat and virulence gene targets. J Med Microbiol. 2010;59(5):541-7. https://doi.org/10.1099/jmm.0.015198-0 PMid:20110386

17. Akbari M, Bakhsi B, Peerayeh SN. Particular distribution of Enterobacter cloacae strains isolated from urinary tract infection within clonal complexes. Iran Biomed J 2016;20(1):49-55. PMid:26498349

18. Choi HJ, Kim MK, Cho MS, Kim BY, Kim JY, Kim CK, et al Improved PCR for identification of Pseudomonas aeruginosa. Appl Microbiol Biotechnol. 2013;97(8):3643-51. https://doi. org/10.1007/s00253-013-4709-0 PMid:23504075

19. Lucignano B, Ranno S, Liesenfeld O, Pizzorno B, Putignani L, Bernaschi P, et al. Multiplex PCR allows rapid and accurate diagnosis of bloodstream infections in newborns and children with suspected sepsis. J Clin Microbiol. 2011;49(6):2252-8. https://doi.org/10.1128/jcm.02460-10

PMid:21471340 